\title{
EFFICACY AND SAFETY OF MISOPROSTOL IN SECOND TRIMESTER MEDICAL TERMINATION OF PREGNANCY AT A TERTIARY LEVEL CENTRE IN KERALA
}

\author{
Mohammed Sidhiq Chundakkadan', Mini C. $H^{2}$
}

${ }_{1}^{1}$ Assistant Professor, Department of Obstetrics and Gynaecology, Calicut Medical College.

2 Professor and HOD, Department of Obstetrics and Gynaecology, Calicut Medical College.

\begin{tabular}{l}
\hline ABSTRACT \\
BACKGROUND \\
Mecond trimester MTP is done by various methods. Most commonly used and studied in various regimens of Mifepristone and \\
drugs without prolongation of induction expulsion interval, patient responded well. Hence, we conducted this study.
\end{tabular}

\section{MATERIALS AND METHODS}

This non-randomised clinical trial of various doses of Misoprostol for second trimester MTP conducted at family welfare unit of Govt. Medical College, Kozhikode, from 1.1.2017 to 31.12,2017. Consecutive patients who satisfy inclusion criteria were divided into 3 groups. All A, B and C group took 600 mg Mifepristone orally and 200, 600 and 800 ug vaginal Misoprostol respectively. After 48 hrs., data was analysed by SPSS 16.0 .

\section{RESULTS}

Majority of second trimester abortion were for anomalous babies (89\%) and 11\% were for medico-legal issues; 600 ug Misoprostol had $90 \%$ success rate.

\section{CONCLUSION}

$600 \mathrm{mg}$ Mifepristone followed by $600 \mathrm{ug}$ Misoprostol had an induction expulsion interval of $<24 \mathrm{hrs}$. and equally efficacious too for the higher doses of Misoprostol regimens.

\section{KEYWORDS}

Mifepristone, Misoprostol.

HOW TO CITE THIS ARTICLE: Chundakkadan MS, Mini CH. Efficacy and safety of misoprostol in second trimester medical termination of pregnancy at a tertiary level centre in Kerala. J. Evolution Med. Dent. Sci. 2018;7(10):1212-1215, DOI: $10.14260 /$ jemds/2018/277

\section{BACKGROUND}

In developing countries like India, contraceptive methods are not widely practiced. In many cases either the pregnancy is unwanted because of social/ ethical reasons, lethal anomaly to the foetus and life-threatening condition for the women or failure of contraceptive.(1)

Medical termination of pregnancy can be done through various regimens.(2) Most commonly used and studied regimen includes that of mifepristone (antiprogesterone) and misoprostol (Synthetic 15-deoxy-16-hydroxy-16-methyl analogue of PGE1).(3) Misoprostol, being much cheaper, safe and capable of being easily stored at room temperature has been tried by both oral and vaginal routes in different dosage regimens with varying degrees of success.(4) Oral misoprostol is associated with faster achievement of peak levels, but the effect lasts for less time and it is also associated with more side effects. However, vaginal route is associated with slower peak level achievement, but the effect lasts longer with fewer

'Financial or Other Competing Interest': None.

Submission 13-12-2017, Peer Review 20-02-2018,

Acceptance 26-02-2018, Published 05-03-2018.

Corresponding Author:

Dr. Mohammed Sidhiq Chundakkadan,

Assistant Professor,

Department of Obstetrics and Gynaecology,

Government Medical College, Kozhikode.

E-mail:cmsidhiq@gmail.com

DOI: $10.14260 /$ jemds $/ 2018 / 277$

\section{(c) $(1)$}

side effects $3-5$. We have used the vaginal route in our study. $(5,6)$

FIGO in 2017 came out with a recommendation on the various dosage regimens for MTP. $(7,8)$ In our institution we have noticed that at even lesser doses of drugs, without undue prolongation of the induction expulsion interval patients respond well. Hence, we have conducted this study to look into the various regimens and to establish their efficacy.

\section{Aim}

To study the efficacy and safety of various regimens of intravaginal misoprostol in Second Trimester Pregnancy Termination.

\section{Objectives}

1. To compare efficacy of various doses of misoprostol used for Second Trimester Medical Termination Regimens.

2. To compare safety of various doses of misoprostol used for Second Trimester Termination of Pregnancy.

3. To identify common indications for Second Trimester Termination Pregnancy.

4. To find out various types of anomalies as indication for second Trimester Termination of Pregnancy.

\section{MATERIALS AND METHODS}

This Non-Randomised Clinical Trial of various doses of misoprostol for 2nd Trimester Termination of Pregnancy at Family Welfare Unit of Government Medical College, Kozhikode, was conducted from $1^{\text {st }}$ January of 2017 to $31^{\text {st }}$ 
December 2017 (1 year). Women between the ages of 18 - 42 years with 10 - 20 weeks of pregnancy requesting second trimester termination of pregnancy at Family Welfare Unit of Government Medical College, Kozhikode.

The Sample Size and Allocation of Study Subjects were taken for Convenience and was divided into Three Groups A, B and C-

Group A: Subjects receiving $600 \mathrm{mg}$ oral mifepristone and $200 \mu \mathrm{g}$ vaginal misoprostol.

Group B: Subjects receiving $600 \mathrm{mg}$ oral mifepristone and $600 \mu \mathrm{g}$ vaginal misoprostol.

Group C: Subjects receiving $600 \mathrm{mg}$ oral mifepristone and $800 \mu \mathrm{g}$ vaginal misoprostol.

\section{Inclusion Criteria}

- Indication for termination were in consonance with MTP Act 1971.

- Singleton pregnancy.

- $\mathrm{Hb}>8 \mathrm{gm} \%$.

\section{Methodology}

Group A: $600 \mathrm{mg}$ mifepristone orally in empty stomach followed by $200 \mu \mathrm{g}$ misoprostol after $48 \mathrm{hrs}$. by vaginal application.

Group B: $600 \mathrm{mg}$ mifepristone orally in empty stomach followed by $600 \mu \mathrm{g}$ misoprostol after $48 \mathrm{hrs}$. by vaginal application.

Group C: $600 \mathrm{mg}$ mifepristone orally in empty stomach followed by $800 \mu \mathrm{g}$ misoprostol after $48 \mathrm{hrs}$. by vaginal application.

If failure to expel within 24 hours was noted, misoprostol was repeated up to a maximum of 3 doses of $400 \mu \mathrm{g}$. Women's vital signs were monitored. The progress of abortion was assessed by vaginal examination during administration of each dose.

Information about side effects was collected from each woman including nausea, vomiting, diarrhoea, fever, excessive bleeding and procedure related complications were noted.

All the women were kept in hospital after expulsion for 24 hrs. under observation. Indications for MTP and common anomalies leading to medical termination of pregnancy were noted. On discharge, patients were asked to come for followup after 4 weeks. On follow-up, general examination and pelvic examination were conducted and information regarding abnormal bleeding, discharge $\mathrm{p} / \mathrm{v}$ or any other delayed side effects was collected.

\section{Statistical Analysis}

Data was analysed by using SPSS 16.0. Data was expressed as frequencies and percentages. Statistical analysis was done using chi-square tests. A 'p' value $<0.05$ was considered to indicate statistical significance.

\section{RESULTS}

Majority (42\%) of the patients were between 20 - 25 years of age and $60 \%$ patients were multiparous.

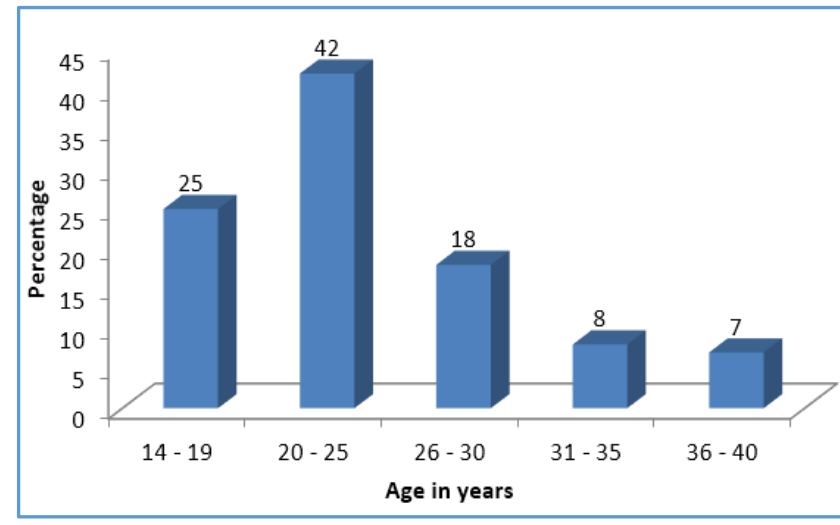

Figure 1. Age-Wise distribution of Patients

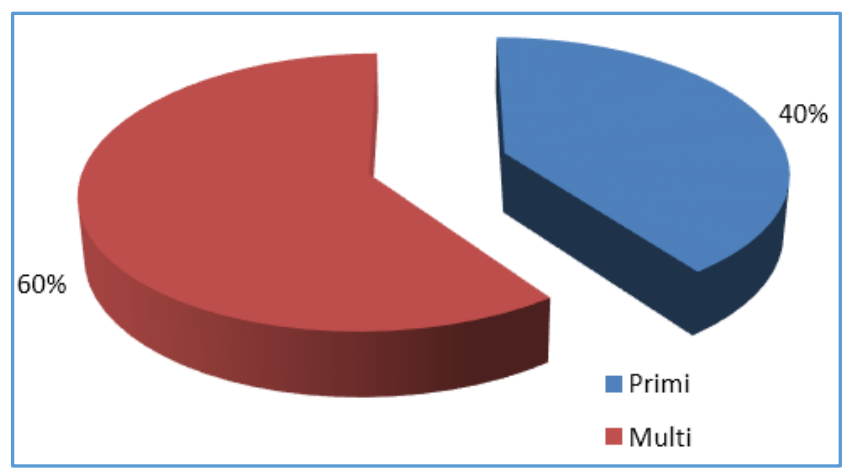

Figure 2. Parity-Wise distribution of the Patients

$50 \%$ of terminations were between $18-20$ weeks of gestational age.



Figure 3. Gestational Age at Termination

$600 \mathrm{mg}$ mifepristone and $600 \mu \mathrm{g}$ misoprostol has $90 \%$ success compared to $200 \mu \mathrm{g}$ and $800 \mu \mathrm{g}$ misoprostol, though it was not statistically significant.

\begin{tabular}{|c|c|c|c|}
\hline Group & Success & Failure & P value \\
\hline A & $13(65 \%)$ & $7(35 \%)$ & \multirow{2}{*}{0.15} \\
\hline B & $18(90 \%)$ & $2(10 \%)$ & \\
\hline C & $14(70 \%)$ & $6(30 \%)$ & \\
\hline \multicolumn{4}{|c|}{ Table 1. Success Rates of various Regimens of Second } \\
Trimester Termination \\
\hline
\end{tabular}




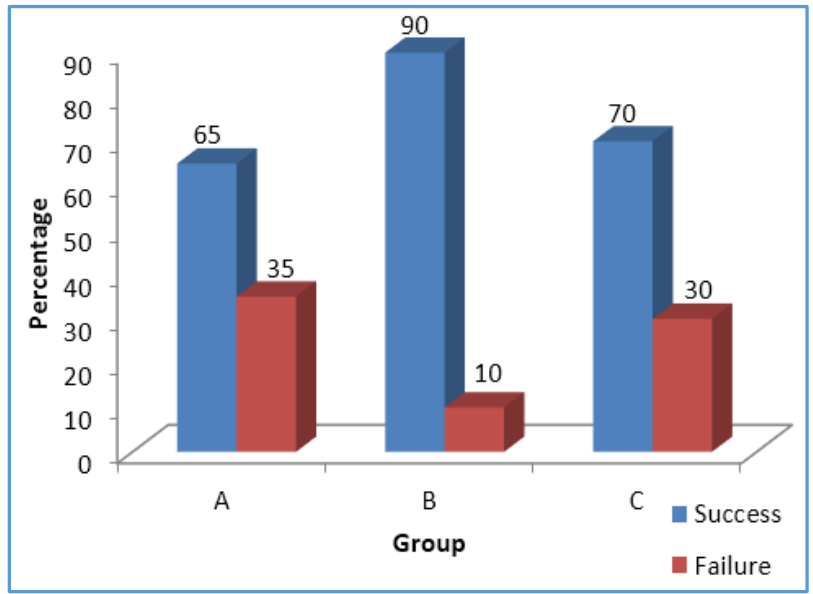

Figure 4. Success Rates of various Regimens of Second Trimester Termination

In the study by Grimes et al, they could not establish superiority with lowered dosing regimens of misoprostol. In their study, the dosage of mifepristone used was $200 \mathrm{mg}$ which was lower than $600 \mathrm{mg}$ in our study. ${ }^{(9)}$

Kulkarni et al on comparing various dosing regimens noted better success when mifepristone $600 \mathrm{mg}$ was utilised and misoprostol was given after $4 \mathrm{hrs}$. between dosages of $200-400 \mu \mathrm{g} .(10,11)$

In our study, only one case $(1.7 \%)$ required blood transfusion in view of pre-existing anaemia and previous thrombocytopenia. 2 cases of MTP with mifepristone $600 \mathrm{mg}$ and misoprostol $800 \mu \mathrm{g}$ required dilatation and curettage procedure.

In the study of Dalve et al increased risk of haemorrhage and perforation were noted with failed medical abortion requiring surgical evacuation as opposed to primary surgical evacuation. Among the study population, 16 cases (26\%) were previous caesarean section cases.

No complications and side effects were noted in the follow-up of the patients.

Majority of $(89 \%)$ second trimester abortions were for anomalous babies or life-threatening malformations, whereas remainder $(11 \%)$ constituted pregnancy out of medico-legal conditions requiring termination.

In the study of Schaff et al, a prevalence of similar indications for MTP were noted.(12)

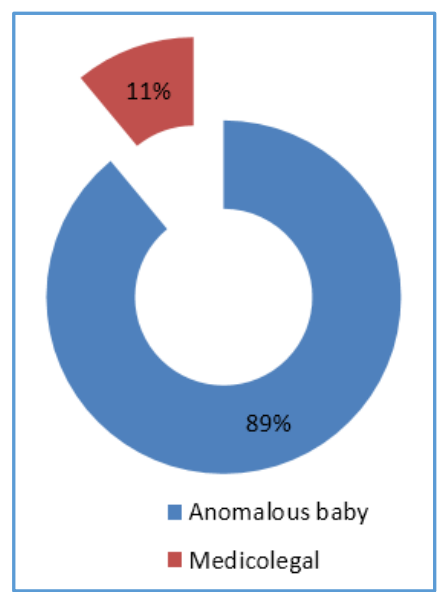

Figure 5. Indication for Second Trimester Termination
Grossman et al in their study also noticed, they had a higher prevalence of neural tube defects followed by cardiovascular defects and abdominal wall defects.(13)

Most common anomalies that led to second trimester termination of pregnancy in our study were hydrops (21\%), anencephaly (18\%), other neural tube defects $(14 \%)$ and meningomyelocele (10\%).

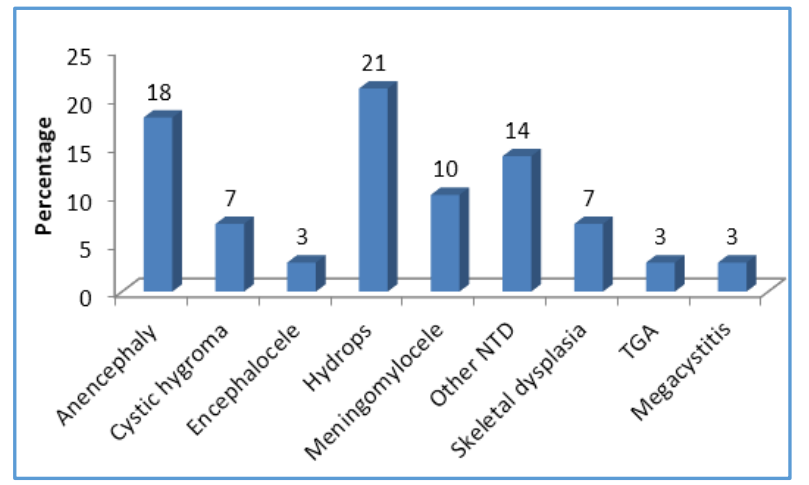

Figure 6. Various Anomalies leading to Second Trimester MTP

\section{DISCUSSION}

Out of 60 women, majority (42\%) were $20-25$ years' age group and $60 \%$ were multiparous. Majority of terminations were for anomalous babies. Commonest anomaly was neural tube defect, same dose was kept for previous cases also. Only one case required blood transfusion, which is a case of thrombocytopenia.

\section{CONCLUSION}

$600 \mathrm{mg}$ mifepristone followed by $600 \mu \mathrm{g}$ misoprostol had an induction expulsion interval $<24 \mathrm{hrs}$. and is equally efficacious when compared to higher doses of misoprostol (800 mg).

This regimen was found to be safe in cases of previous caesarean section with an efficacy of $100 \%$.

In comparison with FIGO 2017 misoprostol recommendations, we found that a lower and less vigorous dosage regimen of mifepristone and misoprostol is efficacious in achieving second trimester MTP.

\section{Limitations of the Study}

Short study period, hence future pregnancy outcome or any long-term complications could not be assessed. Small study population.

\section{REFERENCES}

[1] Dalvie SS. Second trimester abortions in India. Reprod Health Matters 2008;16(Suppl 31):37-45.

[2] Borgatta L, Kapp N. Clinical guidelines. Labor induction abortion in the second trimester. Contraception 2011;84(1):4-18.

[3] Bryant AG, Grimes DA, Garrett JM, et al. Secondtrimester abortion for fetal anomalies or fetal death: labor induction compared with dilation and evacuation. Obstet Gynecol 2011;117(4):788-92.

[4] Cowett AA, Golub RM, Grobman WA. Costeffectiveness of dilation and evacuation versus the induction of labor for second trimester pregnancy termination. Am J Obstet Gynecol 2006;194(3):76873. 


\section{Jemds.com}

[5] Lim LM, Singh K. Methods of abortion in first and second trimester. Open Journal of Gynecology 2014;4(15):924-9.

[6] Von Hertzen H, Piaggio G, Marisons L. Comparison of two doses and two routes of administration of misoprostol after pre-treatment with mifepristone for early pregnancy termination. Reprod Health 2008;5:2.

[7] Nagaria T, Sirmor N. Misoprostol vs mifepristone and misoprostol in second trimester termination of pregnancy. J Obstet Gynaecol India 2011;61(6):65962.

[8] ACOG Practice Bulletin No. 135: Second-trimester abortion. Obstet Gynecol 2013;121(6):1394-406.

[9] Grimes DA, Smith MS, Witham AD. Mifepristone and misoprostol versus dilation and evacuation for midtrimester abortion: a pilot randomized controlled trial. BJOG 2004;111(2):148-53.

\section{Original Research Article}

[10] Kulkarni KK. Pre-induction with mifepristone for second trimester termination of pregnancy. J Obstet Gynaecol India 2014;64(2):102-4.

[11] Kelly T, Suddes J, Howel D, et al. Comparing medical versus surgical termination of pregnancy at 13-20 weeks of gestation: a randomized controlled trial. BJOG 2010;117(12):1512-20.

[12] Schaff EA, Eisinger SH, Stadalius LS, et al. Low-dose mifepristone $200 \mathrm{mg}$ and vaginal misoprostol for abortion. Contraception 1999;59(1):1-6.

[13] Grossman D, Blanchard K, Blumenthal P. Complications after second trimester surgical and medical abortion. Reprod Health Matters 2008;16(Suppl 31):173-82. 